\title{
Impact of Intimate Partner violence on ever married women and utilization of antenatal care services in Tanzania
}

\author{
Russell Kabir, ${ }^{1}$ Anwarul Azim Majumder, ${ }^{2}$ SM Yasir Arafat, ${ }^{3}$ Rocky Khan Chodwhury ${ }^{4}$, Shireen \\ Sultana, ${ }^{5}$ SM Moslehuddin Ahmed, ${ }^{6}$ Dioneia Motta Monte-Serrat, ${ }^{7}$ Esmot Zarin Chowdhury ${ }^{8}$ \\ ${ }^{1}$ Senior Lecturer, Department of Medical Science and Public Health, Faculty of Medical Sciences, Anglia \\ Ruskin University, Chelmsford, Essex, UK. \\ ${ }^{2}$ Director of Medical Education, The University of the West Indies, Barbados \\ ${ }^{3}$ Resident, Department of Psychiatry, Bangabandhu Sheikh Mujib Medical University, Dhaka, Bangladesh \\ ${ }^{4}$ Lecturer, Department of Public Health, First Capital University, Bangladesh \\ ${ }^{5}$ Cognitive Behavioural Therapist, Goodmayes Hospital, Essex, UK \\ ${ }^{6}$ Professor, Department of Community Medicine, Uttara Adhunik Medical College, Bangladesh \\ ${ }^{7}$ Lecturer Health and Education, Universidade de Ribeirao Preto, Sao Paulo State, Brazil \\ ${ }^{8}$ Research Associate, Disabled Rehabilitation \& Research Association, Dhaka, Bangladesh
}

\begin{abstract}
Correspondence
Dr. S.M. Yasir Arafat,

Resident, Department of

Psychiatry, Bangabandhu

Sheikh Mujib Medical

University, Dhaka, Bangladesh.
\end{abstract}

Email:

arafatdmc62@gmail.com

DOI: http://dx.doi.org/10.3126/ jcmsn.v14i1.17802

Orcid ID: orcid.org/0000-0003 $-0521-5708$

Article received: July $16^{\text {th }} 2017$ Article accepted: Feb $11^{\text {th }} 2018$

\begin{abstract}
Background \& Objectives: Sub Saharan Africa region is considered as one of the deprived regions of this world and women from this part of the world are suffering from intimate partner violence. This study was undertaken to assess the impact of intimate partner violence on utilization of antenatal care services among the ever married women. Materials \& Methods: This is a descriptive cross-sectional study design. The data used in this research was extracted from the Tanzania Demographic Health Survey 2015-16. A total of 13, 266 women were interviewed. Results: The mean age of the respondents is 28.69 years. About $74 \%$ women visited antenatal care services more than 4 times. Logistic regression results indicate that the middle-aged adult women (35-49 years age group) were identified having lower odds (Odds ratio: 0.807 , 95\% CI: $0.693-0.940, \mathrm{P}<0.001)$ than women in younger age group. Women who did not complete their secondary education were less likelihood to experience IPV (Odds ratio: 0.705, 95\% CI: 0.540-0.922, $\mathrm{P}<0.010)$. Conclusion: Intimate partner violence is one main challenge to women's health and wellbeing during pregnancy period. Proper implementation and community based interventions to support pregnant women to seek antenatal care services and to raise awareness regarding intimate partner violence are advocated.
\end{abstract}

Key words: Antenatal Care; Intimate partner violence; pregnant women.

Citation: Kabir R, Majumder AA, Arafat SMY, Chodwhury RK; Sultana S, Ahmed SMM, et al. Impact of Intimate Partner violence on ever married women and utilization of antenatal care services in Tanzania. JCMS Nepal. 2018;14(1):7-13.

\section{INTRODUCTION}

Reproductive health is a vital part of general health system and is of special importance for women especially of reproductive years. ${ }^{1}$ Worldwide $80 \%$ of maternal deaths occur due to causes related to pregnancy. $^{2}$ The progress to reduce maternal mortality is very slow despite the international emphasis on the need to address unmet health needs of women. ${ }^{3}$ WHO recommends ante natal care (ANC) visits provide an excellent opportunity for pregnant women to receive education regarding the danger signs and symptoms during pregnancy, delivery and postnatal period and information on family planning and birth spacing.4 Intimate partner violence (IPV) is one the most common forms of violence against women. ${ }^{5}$ It is also referred to as 'domestic violence', 'battering' or 'spousal abuse'. ${ }^{6}$ Violence during pregnancy directly or indirectly leads to adverse health effects for the infant during pregnancy, birth and postnatal period. ${ }^{7}$ 
In Tanzania, like other Sub-Saharan Africa countries maternal mortality considered to be one of the biggest problem. ${ }^{8}$ Maternal mortality ratio (MMR) is 578 per 100000 cases represent 18 percent of all deaths of women age 15 to 49 . The main causes of maternal mortality are haemorrhages, infections, unsafe abortions, hypertensive disorders and obstructed labours. ${ }^{9}$

There is significant association between utilization of maternal health care services and IPV. ${ }^{10}$ But some research found that there is no significant association between IPV and utilization of antenatal care services in Zambia. ${ }^{11}$ Present study aimed to assess the impact of interpersonal violence on utilization of antenatal care by women of Tanzania.

\section{MATERIALS AND METHODS Study Area and Population}

The research was conducted in urban and rural areas of Tanzania Mainland and Zanzibar. The study design used in this research is descriptive cross-sectional. The data used in this research was extracted from the Tanzania Demographic Health Survey 2015-16. ${ }^{12}$ The study population for this research was women age between 15 to 49 . Multistage cluster sampling was used to select the sample for this survey. Data was collected from 30 geographic regions of Tanzania Mainland and Zanzibar (25 regions of Tanzania Mainland and 5 regions from Zanzibar). The urban and rural areas of each region form a sampling stratum. Samples were selected independently from each sampling stratum using two stage selections. In the first stage a total of 59 stratums were selected and samples were selected independently from each sampling stratum. The survey selected 608 clusters (180 EAs from urban areas and 428 from rural areas) standard enumeration areas from the strata. In the second stage, a fixed number of 22 households were selected per cluster and a total number of households were selected is 13376 and among them 3,960 households were from urban areas and 9416 households from rural areas. A total of 16, 780 respondents were selected for this survey and about 13,266 of them are women and 3,514 are men. ${ }^{12}$ But for this research only 13,266 women participants age between 15 to 49 years were selected.

\section{Study Material and Measures}

Tanzania Demographic Health and Survey 2015-16 using four different types of questionnairehousehold questionnaire, woman's questionnaire, man's questionnaire and biomarker
questionnaire16.This research has used woman's questionnaire. Close ended questionnaire was used. Data collection started in August 2015 and ended in February 2016. To maintain ethical issues prior consent was obtained from the participant before to data collection and they were explained about the purpose of the research and involvement was voluntary.

\section{Data Analysis}

Data were analyzed using Statistical Software SPSS version 20.0. The probability of significance was set at 5\% level of significance for all tests and $95 \%$ confidence interval. Frequency distribution, ChiSquare and bivariate logistic regression analysis was carried out using odds ratio as both the dependent variables of this research are categorical. For data analysis purpose, two types of variables are used in this research and description of those variables are given below.

\section{Dependent Variables}

This research has used two dependent variables. The first dependent variable is Intimate Partner Violence (IPV) and it was determined by combination of physical violence, sexual violence and emotional violence. Physical violence was determined by respondent answering "yes" to any of a string of questions about whether her spouse ever did the following - (1) pushed, shook or threw something at her (2) slapped her (3) punched her (4) kicked or dragged her (5) strangled or burnt her (6) threatened or attacked her with a knife, gun or any other weapons. Sexual violence was determined by the respondent answering "yes" to any of the two following questions- (1) ever been physically forced into unwanted sex and (2) ever been forced into other unwanted sexual acts. Emotional violence was determined by respondent answering "yes" to ever experience emotional violence. The other independent variable of this research is ANC visit. It was measured using the question that how many times they received antenatal care during pregnancy. ANC visit was recorded as "0" when the respondents made one to three visits and it was recorded as " 1 " when they made four or more ANC visits.

\section{Independent Variables}

Women's characteristics such as age of the respondent, wealth index, place of residence, educational attainment, occupational status and number of children five and under were considered as first set independent variable. Husband characteristics such as educational attainment, drinks alcohol, husband jealous and witnessed 
parental beating were also determined as first set of independent variables. In the second set of variable IPV was considered as independent variable.

\section{RESULTS}

The background characteristics of the women from Tanzania are shown in Table 1 . The mean age of the respondents is 28.69 years. About $41 \%$ respondents age were between 15 to 24 years of age. Approximately 30\% respondent's age are between 35-49 years. Majority of the respondent about $68 \%$ of them were from rural area and $31 \%$ from urban area. About 57.6\% respondents had completed primary education and $15 \%$ of them had no education. A clear majority of the respondent (71.5\%) were currently working and about $28.4 \%$ of them have no work. Only $1.2 \%$ households had six or more children. About $25.7 \%$ of the

Table 1 Background Characteristics of the respondents

\begin{tabular}{|c|c|c|}
\hline Categories & Frequency & $\%$ \\
\hline \multicolumn{3}{|c|}{ Age of the respondent } \\
\hline $15-24$ & 5399 & 40.7 \\
\hline $25-34$ & 3856 & 29.1 \\
\hline $35-49$ & 4011 & 30.2 \\
\hline Mean \pm SD & $28.69 \pm 9.7$ & \\
\hline \multicolumn{3}{|c|}{ Type of place of residence } \\
\hline Urban & 4145 & 31.2 \\
\hline Rural & 9121 & 68.8 \\
\hline
\end{tabular}

Highest educational level

\begin{tabular}{lll} 
No education & 1998 & 15.1 \\
\hline Primary & 7640 & 57.6 \\
\hline Secondary & 3487 & 26.3 \\
Higher & 141 & 1.1
\end{tabular}

\section{Occupational Status}

$\begin{array}{lll}\text { Yes } & 9489 & 71.5 \\ \text { No } & 3773 & 28.4\end{array}$

Number of children 5 and under in household

\begin{tabular}{lll}
0 & 3714 & 28 \\
2-Jan & 7821 & 59 \\
\hline 5-Mar & 1569 & 11.8 \\
\hline $6+$ & 162 & 1.2 \\
\hline Wealth index & & \\
\hline Poorest & 2144 & 16.2 \\
\hline Poorer & 2166 & 16.3 \\
\hline Middle & 2438 & 18.4 \\
\hline Richer & 3108 & 23.4 \\
\hline Richest & 3410 & 25.7 \\
\hline
\end{tabular}

respondents were coming from richest households, only $18.4 \%$ respondents participated from middle class households and $16 \%$ respondents from poorest households.

Table 2 shows the characteristics of respondent's husband. About $64 \%$ respondents' husband completed primary education and about $13 \%$ of respondent's husband had no education. About 31\% respondents revealed that their husband or partner drink alcohol. Approximately, 33.3\% respondents shared that husband become jealous if they see them talking to another man.

Table 3 highlights the relationships between IPV and socio-demographic characteristics of women and their spouse based on logistic regression analysis. The type of residence and husband educational attainment did not show any significant effects on IPV. Table 9 also showed that women in younger age group (15-24 years age group) had higher risk to be abused by inmate partners and the risk of being abused declined with the increase of age. The middle-aged adult women (35-49 years age group) were identified having lower odds (Odds ratio: $0.807,95 \% \mathrm{CI}: 0.693-0.940, \mathrm{P}<0.001)$ than women in younger age group. Women who did not completed their primary education had more chance to experience IPV (Odds ratio: 1.248, 95\% CI: $1.022-1.524, \quad \mathrm{P}<0.030)$ than those who had no

Table 2: Characteristics of respondent's husband

\begin{tabular}{lll}
$\begin{array}{l}\text { Categories } \\
\text { Husband/partner's } \\
\text { educational level }\end{array}$ & Frequency & $\mathbf{\%}$ \\
\hline No education & 1062 & 13 \\
\hline Primary & 5292 & 64.6 \\
\hline Secondary & 1563 & 19.1 \\
\hline Higher & 241 & 2.9 \\
\hline Don't Know & 31 & 0.4
\end{tabular}

\begin{tabular}{lll}
$\begin{array}{l}\text { Husband/partner drinks } \\
\text { alcohol }\end{array}$ & & \\
\hline No & 5208 & 68.6 \\
\hline Yes & 2389 & 31.4 \\
\hline Husband Jealous & & \\
\hline No & 3106 & 23.4 \\
Yes & 4412 & 33.3 \\
\hline Don't Know & 78 & 0.6 \\
\hline
\end{tabular}

Witnessed parental violence

$\begin{array}{lll}\text { No } & 5563 & 41.9 \\ \text { Yes } & 2979 & 22.5 \\ \text { Don't know } & 780 & 5.9\end{array}$


Original Research Article

Table 3: Logistic regression results of IPV and woman and husband's characteristics

Variables

Ever experienced IPV

Odds ratio $\quad 95 \%$ CI

$p$-value

Age of the respondent

$15-24$

25-34

0.974

1

$35-49$

0.807

$0.844-1.125<.72$

$0.693-0.940<.00$

Type of residence

Urban

Rural

0.881

1

Educational attainment

No education

Incomplete primary

Complete primary

Incomplete secondary

$0.747-1039<.13$

Complete secondary

Higher

0.881

Wealth Index

Poorest

Poorer

Middle

0.857

1.248

1

Richer

1.063

$1.022-1.524$

$<.03$

0.705

$0.910-1.241$

$<.44$

0.723

$0.540-0.922$

$<.01$

0.677

$0.554-0.943$

$<.01$

Richest

0.723

$0.310-1.479$

$<.32$

\section{Occupational Status}

No

Yes

Number children 5 and under

0

2-Jan

0.688

1

5-Mar

1.334

$0.717-1.024$

$<.09$

$0.691-0.987$

$<.03$

$6^{+}$

2.261

$0.598-0.873<.00$

$0.539-0.878<.00$

\section{Husbands Educational Attainment}

No education

Primary

Secondary

1.094

0.804

1

Higher

0.721

$1.212-1.603$

$<.00$

Don't know

1.695

1

Drinks alcohol

No

$0.929-1.224<.36$

$1.084-1.640<.00$

$0.994-5.114<.05$

Yes

2.508

1

Husband jealous

No

Yes

3.068

Don't know

0.928

2.736-3.442

$<.00$

Witnessed beating

No

Yes

Don't Know

2.498

1

1.606

2.218-2.812

$<.00$

10

1.322-1.952

$<.00$ 
Table 4: Logistic regression showing woman's and husband characteristics and intimate partner violence with use ANC services

\begin{tabular}{|c|c|c|c|}
\hline \multirow[t]{2}{*}{ Variables } & \multicolumn{3}{|l|}{ Use of ANC } \\
\hline & Odds ratio & $95 \% \mathrm{CI}$ & $p$-value \\
\hline \multicolumn{4}{|l|}{ Ever Experienced IPV } \\
\hline No & & 1 & \\
\hline Yes & 0.913 & $0.800-1.042$ & $<0.17$ \\
\hline \multicolumn{4}{|l|}{ Age of the respondent } \\
\hline $15-24$ & & 1 & \\
\hline $25-34$ & 0.925 & $0.798-1.071$ & $<0.29$ \\
\hline $35-49$ & 0.847 & $0.715-1.002$ & $<0.05$ \\
\hline \multicolumn{4}{|l|}{ Type of residence } \\
\hline Urban & & 1 & \\
\hline Rural & 0.977 & $0.815-1.172$ & $<0.80$ \\
\hline \multicolumn{4}{|c|}{ Educational attainment } \\
\hline No education & & 1 & \\
\hline Incomplete primary & 0.957 & $0.772-1.186$ & $<0.68$ \\
\hline Complete primary & 1.157 & $0.981-1.365$ & $<0.08$ \\
\hline Incomplete secondary & 0.894 & $0.683-1.171$ & $<0.41$ \\
\hline Complete secondary & 1.567 & $1.176-2.088$ & $<0.00$ \\
\hline Higher & 3.113 & $1.129-8.586$ & $<0.02$ \\
\hline \multicolumn{4}{|l|}{ Wealth index } \\
\hline Poorest & & 1 & \\
\hline Poorer & 0.907 & 0.751-1.094 & $<0.30$ \\
\hline Middle & 1.029 & $0.853-1.243$ & $<0.76$ \\
\hline Richer & 1.569 & $1.280-1.924$ & $<0.00$ \\
\hline Richest & 1.747 & $1.337-2.282$ & $<0.00$ \\
\hline \multicolumn{4}{|l|}{ Occupational Status } \\
\hline No & & 1 & \\
\hline Yes & 1.005 & $0.869-1.162$ & $<.94$ \\
\hline \multicolumn{4}{|c|}{ Number children 5 and under } \\
\hline 0 & & 1 & \\
\hline 2-Jan & 0.818 & $0.605-1.106$ & $<0.19$ \\
\hline 5-Mar & 0.576 & $0.411-0.807$ & $<0.00$ \\
\hline $6+$ & 0.253 & $.091-0.706$ & $<0.00$ \\
\hline \multicolumn{4}{|c|}{ Husbands Educational Attainment } \\
\hline No education & & 1 & \\
\hline Primary & 1.268 & $1.065-1.553$ & $<0.00$ \\
\hline Secondary & 1.473 & $1.152-1.881$ & $<0.00$ \\
\hline Higher & 1.383 & $0.824-2.321$ & $<0.22$ \\
\hline Don't know & 1.799 & $0.616-5.248$ & $<0.28$ \\
\hline \multicolumn{4}{|l|}{ Drinks alcohol } \\
\hline No & & 1 & \\
\hline Yes & 0.877 & $0.762-1.010$ & $<0.06$ \\
\hline \multicolumn{4}{|l|}{ Husband jealous } \\
\hline No & & 1 & \\
\hline Yes & 1.287 & $1.135-1.461$ & $<0.00$ \\
\hline Don't know & 1.669 & $0.924-3.017$ & $<0.06$ \\
\hline \multicolumn{4}{|l|}{ Witnessed beating } \\
\hline No & & 1 & \\
\hline Yes & 0.951 & $0.915-1.416$ & $<0.46$ \\
\hline Don't Know & 1.138 & $0.800-1.042$ & $<0.24$ \\
\hline
\end{tabular}


education. Women found to experience IPV more who belonged to lower socio-economic status. Women who had job were more likely to experience IPV (Odds ratio: 1.394, 95\% CI: 1.212$1.603, \mathrm{P}<0.001)$ than who had not. Women whose husband felt jealous had more than 3 times higher chance to experience IPV (Odds ratio: 3.068, 95\% CI: 2.736-3.442, $\mathrm{P}<0.001)$ than those whose husband were not jealous.

The results of logistic regression analysis highlighting the relationships between use of ANC services and socio-demographic characteristics of women and their spouse presented in Table 4.The women in younger age group (15 to 24 years age group) had higher chance to take ANC and the chance reduced with the increase of age. The middle-aged adult women (35 to 49 years age group) were less likely to take ANC (Odds ratio: $0.847,95 \%$ CI: $0.715-1.002, \mathrm{P}<0.050$ ) than women in younger age group. In contrast, women who completed their secondary (Odds ratio: $1.567,95 \%$ CI: 1.176-2.088, $\mathrm{P}<0.010)$ and higher education (Odds ratio: 3.113 , 95\% CI: 1.129-8.586, $\mathrm{P}<0.020$ ) were more likelihood to take ANC than those who had no education. Similarly, Women who belonged to richer (Odds ratio: $1.569,95 \%$ CI: $1.280-1.924$, $\mathrm{P}<0.001$ ) and richest (Odds ratio: $1.747,95 \% \mathrm{CI}$ : 1.337-2.282, $\mathrm{P}<0.001$ ) in terms of socio-economic status were more likelihood to take ANC than those who were poorer. Women with 3-5 children were less likely to take ANC (Odds ratio: 0.576, 95\% CI: 0.411-0.807, $\mathrm{P}<0.001)$ than those who had no children. Once again, women with more than 6 children had 75\% less chance to take ANC (Odds ratio: $0.253,95 \% \mathrm{CI}: 0.091-0.706, \mathrm{P}<0.001)$ than those who had no children.

\section{DISCUSSION}

The study result revealed that the mean age of the respondents is 28.69 years and about $41 \%$ of the respondent's age is between 15 to 24 years of age. This is consistent with another research conducted in Nepal and the research found the mean age of the respondents was 25.5 years and majority of the respondents $(44 \%)$ of them were belong to age group less than 25 years. 13 The participants of this research are mostly from $(68 \%)$ rural area and $57.6 \%$ of them completed primary education. Another research identified that about $78.3 \%$ of them were living in rural area and only $26.4 \%$ of them had no education. ${ }^{14}$ About $71 \%$ respondents are currently working but a study done in
Bangladesh found that $72.4 \%$ respondents had no jobs. ${ }^{14}$ This is due to the fact that cultural norms do not allow women to work outside home specially the pregnant women. Respondents from 15 to 24 years age group are more likely to face IPV, this is inconsistent with another finding from a research in central hospital of Benin City, Nigeria where the researcher found that violence was highest among age group between 25 to 34 years. ${ }^{15}$ The statistics show that about $74 \%$ Tanzanian women received four or more antenatal care visits but another similar study was in Nepal had shown that $41 \%$ women had completed the four ANC visit. ${ }^{16}$ Husbands education is an important factor for determination of domestic violence. Respondent's husband who completed primary education are more going to abuse their partners. This was consistent with a finding from Rwanda where they cited that husband's level of education was significantly associated with spousal violence. ${ }^{17,18}$ The logistic regression analysis of this research present that intimate partner violence did not show any significant relationship with ANC visit. Women who had experienced spousal violence made at least four ANC visits which is higher than among women who had not experienced any violence. ${ }^{19}$ In Pakistan, researchers reported that ANC visit is associated with domestic violence. ${ }^{20}$ Other categories like age of the respondents, educational attainment, and wealth index, number of children in the households, husband's educational attainment and jealousy of husband found to have significant association with ANC visits. These findings are consistent with other researches. ${ }^{19-22}$

\section{LIMITATIONS}

One of the limitations of this research is that crosssectional study design which does not show association between dependent and independent variables. Another limitation of this research is recall bias of the respondents and could impact the findings of the research.

\section{CONCLUSION}

Intimate partner violence is a major problem in Tanzania and the young married women are vulnerable to IPV which is affecting their maternal health and pregnancy outcomes. This study revealed that a good number of women are using four or more antenatal care visits. Although the research could not show significant relationship 
between IPV and antenatal care visits but it provides a direction that there is a need to make sure that women should have easy access to information related to antenatal care services.

\section{Funding}

None

\section{Conflict of Interest Statement:}

None Declared

\section{REFERENCES}

1. Geetika S, Mohan L, Tejbir S, Shyam DS. To study the utilization of antenatal care services among pregnant women of rural Amritsar: An interventional study. Int $\mathrm{J}$ Curr Res. 2015;7(5):15789-15792.

2. Kvåle $\mathrm{G}$, Olsen $\mathrm{BE}$, Hinderaker SG, Ulstein $\mathrm{M}$, Bergsjø $\mathrm{P}$. Maternal deaths in developing countries: A preventable tragedy. Norsk Epidemiologi. 2009;15(2):141-149. https:// doi.org/10.5324/nje.v15i2.212.

3. Tsegay Y, Gebrehiwot T, Goicolea I, Edin K, Lemma H., and Sebastian MS. Determinants of antenatal and delivery care utilization in Tigray region, Ethiopia: a cross-sectional study. Int J Equity Health. 2013;12(1):30. https:// doi.org/10.1186/1475-9276-12-30. PMID: 23672203.

4. WHO. Antenatal care in developing countries: Promises, Achievements and Missed Opportunities. 2003; Geneva,World Health Organization.

5. Watts C, Zimmerman C. Violence against women: global scope and magnitude. The lancet. 2002:359(9313):1232-7. https://doi.org/10.1016/S0140-6736(02)08221-1. PMID: 11955557.

6. Usta J, Farver JAM, Pashayan N. Domestic violence: the Lebanese experience. Public health. 2007;121(3): 208-19. https://doi.org/10.1016/j.puhe.2006.09.014.

PMID: 17174993

7. Audi CAF, Segall-Corrêa AM, Santiago SM, PérezEscamilla R. Adverse health events associated with domestic violence during pregnancy among Brazilian women. Midwifery. 2012;28(4):416-21. https:// doi.org/10.1016/j.midw.2011.05.010. PMID: 21775034

8. Mpembeni RN, Killewo JZ, Leshabari MT, Massawe SN, Jahn A, Mushi D, et al. Use pattern of maternal health services and determinants of skilled care during delivery in Southern Tanzania: implications for achievement of MDG5 targets. BMC Pregnancy Childbirth. 2007;7(1):29. https:// doi.org/10.1186/1471-2393-7-29. PMID: 18053268 .

9. National Bureau of Statistics (NBS) [Tanzania] and ORC Macro. Tanzania Demographic and Health Survey 2004-05. 2005. Dar es Salaam, Tanzania: National Bureau of Statistics and ORC Macro.

10. Ononokpono DN, Azfredrick EC. Intimate partner violence and the utilization of maternal health care services in Nigeria. Health Care Women Int. 2014;35(7-9),973-89. https://doi.org/10.1080/07399332.2014.924939.

PMID: 24902004.

11. Simona SJ, Mazuba M, Harriet N. Intimate Partner Violence (IPV) in Zambia: Sociodemographic Determinants and Association with Use of Maternal Health Care. 2015. DHS Working Papers No. 121. Rockville, Maryland, USA: ICF International.

12. Ministry of Health, Community Development, Gender, Elderly and Children (MoHCDGEC) [Tanzania Mainland], Ministry of Health (MoH) [Zanzibar], National Bureau of Statistics (NBS), Office of the Chief Government Statistician (OCGS), and ICF. Tanzania Demographic and Health Survey and Malaria Indicator Survey (TDHS-MIS) 2015-16. 2016. Dar es Salaam, Tanzania, and Rockville, Maryland, USA: MoHCDGEC, MoH, NBS, OCGS, and ICF.

13. Shrestha M, Shrestha S, Shrestha B. Domestic violence among antenatal attendees in a Kathmandu hospital and its associated factors: a cross-sectional study. BMC pregnancy childbirth. 2016;16(1),360. https://doi.org/10.1186/s12884016-1166-7. PMID: 27871256

14. Rahman M, Nakamura K, Seino K, Kizuki M. Intimate partner violence and use of reproductive health services among married women: evidence from a national Bangladeshi sample. BMC Public Health. 2012;12(1):913. https://doi.org/10.1186/1471-2458-12-913.

PMID: 23102051.

15. Ogboghodo EO, Omuemu VO. Prevalence, pattern and determinants of domestic violence among ante-natal clinic attendees in a secondary health facility in Benin City, Edo State. J Com Med Pr Health Care. 2016;28(1):65-75.

16. Pokhrel BR, Parajuli SB, Khatiwada S, Adhikari C. Utilization of Maternal Health Care Services in Kihun Village Development Committee of Tanahun District of Nepal. BJHS. 2017;1(1):56-60. http://dx.doi.org/10.3126/ bjhs.v1il.17101.

17. Rurangirwa AA, Mogren I, Ntaganira J, Krantz G. Intimate partner violence among pregnant women in Rwanda, its associated risk factors and relationship to ANC services attendance: a population-based study. BMJ Open. 2017;7 (2):e013155. https://doi.org/10.1136/bmjopen-2016013155. PMID: 28399509.

18. Karaoglu L, Celbis O, Ercan C, Ilgar M, Pehlivan E, Gunes G, Genc MF, Egri M. Physical, emotional and sexual violence during pregnancy in Malatya, Turkey. Eur J Public Health. 2006;16(2):149-56. https://doi.org/10.1093/eurpub/ cki161. PMID: 16157613 .

19. Tuladhar S, Khanal KR, Lila KC, Ghimire PK, Onta K Women's Empowerment and Spousal Violence in Relation to Health Outcomes in Nepal: Further analysis of the 2011 Nepal Demographic and Health Survey. 2013. Calverton, Maryland, USA: Nepal Ministry of Health and Population, New ERA, and ICF International.

20. Ferdous N, Kabir R, Khan HTA, Chowdhury MRK. Exploring the relationship of domestic violence on health seeking behavior and empowerment of women in Pakistan. Epidemiol Biostat Public Health. 2017;14(1):e12231. https://doi.org/10.2427/12231.

21. Varma D, Chandra PS, Thomas T, Carey MP. Intimate partner violence and sexual coercion among pregnant women in India: relationship with depression and posttraumatic stress disorder. J Affect Disord. 2007;102(1):227 -35. https://doi.org/10.1016/j.jad.2006.09.026. PMID: 17109969.

22. Silverman JG, Gupta J, Decker MR, Kapur N, Raj A. Intimate partner violence and unwanted pregnancy, miscarriage, induced abortion, and stillbirth among a national sample of Bangladeshi women. BJOG. 2007;114 (10):1246-52. https://doi.org/10.1016/j.jad.2006.09.026. PMID: 17109969. 